\title{
Insecticidal Toxicity of Yersinia frederiksenii Involves the Novel Enterotoxin YacT
}

\author{
Katharina Springer ${ }^{1}$, Philipp-Albert Sänger ${ }^{2}$, Christian Moritz ${ }^{1}$, Angela FelsI ${ }^{1}$, \\ Thomas Rattei ${ }^{3}$ and Thilo M. Fuchs ${ }^{1,2 *}$ \\ 1 Lehrstuhl für Mikrobielle Ökologie, Fakultät für Grundlagen der Biowissenschaften, Wissenschaftszentrum Weihenstephan, \\ Technische Universität München, Freising, Germany, ${ }^{2}$ Friedrich-Loeffler-Institut, Institut für Molekulare Pathogenese, Jena, \\ Germany, ${ }^{3}$ Department of Computational Systems Biology, University of Vienna, Vienna, Austria
}

The genus Yersinia comprises 19 species of which three are known as human and animal pathogens. Some species display toxicity toward invertebrates using the so-called toxin complex (TC) and/or determinants that are not yet known. Recent studies showed a remarkable variability of insecticidal activities when representatives of different Yersinia species (spp.) were subcutaneously injected into the greater wax moth, Galleria mellonella. Here, we demonstrate that $Y$. intermedia and $Y$. frederiksenii are highly toxic to this insect. A member of $Y$. Enterocolitica phylogroup 1B killed G. mellonella larvae with injection doses of approximately 38 cells only, thus resembling the insecticidal activity of Photorhabdus luminescens. The pathogenicity Yersinia spp. displays toward the larvae was higher at $15^{\circ} \mathrm{C}$ than at $30^{\circ} \mathrm{C}$ and independent of the TC. However, upon subtraction of all genes of the low-pathogenic Y. enterocolitica strain W22703 from the genomes of $Y$. intermedia and $Y$. frederiksenii, we identified a set of genes that may be responsible for the toxicity of these two species. Indeed, a mutant of Y. frederiksenii lacking yacT, a gene that encodes a protein similar to the heat-stable cytotonic enterotoxin (Ast) of Aeromonas hydrophila, exhibited a reduced pathogenicity toward G. mellonella larvae and altered the morphology of hemocytes. The data suggests that the repertoire of virulence determinants present in environmental Yersinia species remains to be elucidated.

Keywords: Yersinia, Galleria mellonella, insecticidal activity, enterotoxin, YacT

\section{INTRODUCTION}

The genus Yersinia so far consists of three human pathogens (Y. pestis, Y. pseudotuberculosis, and $Y$. enterocolitica), and at least 16 species are considered mostly harmless to humans, namely $Y$. aldovae, Y. bercovieri, Y. frederiksenii, Y. intermedia, Y. kristensenii, Y. mollaretii, Y. rohdei, and the more recently described Y. ruckeri, a fish pathogen (Sulakvelidze, 2000), Y. aleksiciae (Sprague and Neubauer, 2005), Y. similis (Sprague et al., 2008), Y. massiliensis (Merhej et al., 2008), Y. nurmii (Murros-Kontiainen et al., 2010a), Y. pekkanenii (Murros-Kontiainen et al., 2010b), Y. wautersii (Savin et al., 2014), and Y. entomophaga (Hurst et al., 2010). These species that are non-pathogenic for humans have been isolated from water, soil, food, domestic and wild animals, and human beings in which they do not cause any clinical infections.

While the virulence properties of the pathogenic species have been characterized during last few decades, much less is known about the determinants that allow Yersinia species to survive in the 
environment. We have recently demonstrated that the $Y$. enterocolitica strain W22703 (biotype 2, serotype O: 9) is toxic to nematodes and larvae of the tobacco hornworm, Manduca sexta, upon oral infection or oral toxin application, and that this insecticidal activity correlates with the presence of the pathogenicity island (TC-PAI ${ }^{Y e}$ ) (Bresolin et al., 2006; Spanier et al., 2010). This 20-kb fragment is present in the genome of Y. pestis, Y. pseudotuberculosis, and Y. enterocolitica biotype 25 strains, but is absent in the genomes of the highly-pathogenic biotype 1B strains, including 8081 and of the most biotype 1A strains, which are considered to be non-pathogenic to humans. The TC-PAI ${ }^{Y e}$ carries the toxin complex (TC) genes with high identity to the $t c$ genes of entomophagous Photorhabdus luminescens, and it might be speculated that the TC is required to penetrate the epithelial cell barrier of the insect gut to allow $Y$. enterocolitica cells to enter the hemocoel. In Y. entomophaga MH96, an insecticidal pathogenicity island termed PAIYe96 was characterized, which is distinct from TC-PAI ${ }^{Y e}$ in terms of gene homology and genetic organization (Hurst et al., 2011). A unique feature of this island is that it encodes, besides the type ABC genes, two chitinases that are associated with the mature TC (Busby et al., 2012).

The transcription of the tc genes in $Y$. enterocolitica is subject to a strict temperature-dependent regulation as they are completely silenced at $37^{\circ} \mathrm{C}$, but strongly upregulated at lower temperatures with a maximal transcription at $10-15^{\circ} \mathrm{C}$ approximately (Bresolin et al., 2006; Starke et al., 2013; Starke and Fuchs, 2014). Thus, the TC-dependent activity of Y. enterocolitica to invertebrates is reciprocally regulated in comparison with that of many Yersinia virulence factors directed against humans (Marceau, 2005). Notably, strains lacking the insecticidal genes, including Y. enterocolitica, Y. mollaretii, Y. bercovieri, Y. ruckeri, and $Y$. aldovae, are still toxic when subcutaneously injected into G. mellonella, indicating the presence of yet unknown insecticidal determinants in these species (Fuchs et al., 2008). More recently, it was demonstrated that $Y$. enterocolitica strains of phylogroup 1 exhibit a strong virulence against G. mellonella larvae at temperatures of $25^{\circ} \mathrm{C}$ and higher upon intrahemocoelic injection, independently of the presence of virulence plasmid pYV (Alenizi et al., 2016). These findings resemble functional redundancy in $P$. luminescens that carries a set of insecticidal factors besides the TC (ffrench-Constant et al., 2007), including the makes caterpillars floppy (MCF) toxins (Daborn et al., 2002), the Pir toxins (Waterfield et al., 2005), the protease PrtA (Bishop, 2014), Txp40 (Brown et al., 2006), the XaxAB-like binary toxins (Zhang et al., 2014), and the Photorhabdus virulence cassettes (Yang et al., 2006). Interestingly, the (partial) loss of some of these insecticidal genes does not result in a lack of toxicity to invertebrates (Wilkinson et al., 2009).

The insecticidal determinants of some Yersinia spp. remain to be investigated. Here, we used an established infection assay with G. mellonella larvae to monitor the phenotype of the host intrahemocoelically infected with $Y$. frederiksenii, $Y$. intermedia, P. luminescens, and Y. enterocolitica 8081 and W22703 cells. Dose- and temperature-dependent characteristics of their insecticidal activity were determined, and genome comparison as well as toxin injection were applied to gain further insights into the entomopathogenic repertoire of environmental Yersinia strains.

\section{RESULTS}

Dose-dependent toxicity of $Y$. frederiksenii and $Y$. intermedia to G. mellonella larvae. When larvae of the first-instar neonates of $M$. sexta were challenged orally with $Y$. frederiksenii and $Y$. intermedia in preliminary experiments, the toxicity was calculated as 71 and 19\%, respectively (Table 1). As both strains used here lack the TC-PAI ${ }^{Y e}$, we switched from this oral infection model to a subcutaneous infection model and injected $5 \mu \mathrm{l}$ of a 1:100 dilution of $Y$. frederiksenii and $Y$. intermedia overnight culture into G. mellonella larvae, and observed a 99-100\% lethality after 5 days of incubation at $15^{\circ} \mathrm{C}$ (Table 1). Thus, the insecticidal activity of $Y$. frederiksenii and $Y$. intermedia is higher than that of all other Yersinia strains tested recently in the same infection model, including $Y$. enterocolitica strain W22703 (biotype 2, serotype O:9) (Fuchs et al., 2008). To determine the toxicity of $Y$. intermedia and $Y$. frederiksenii toward G. mellonella larvae in more detail, we used defined infection aliquots of approximately $10^{3}-10^{4}$ colony forming units (CFU), and monitored the fate of intrahemocoelically infected G. mellonella larvae over 5 days at room temperature $\left(20^{\circ} \mathrm{C}\right)$ (Figure 1A). The timecourse revealed that all larvae survived for $24 \mathrm{~h}$, but most of them died within the next 2 days. The survival rates of the animals infected with two Yersinia species did not significantly $(p>0.05)$ differ under the conditions applied here. In parallel, we homogenized two larvae each day, and monitored the replication of $Y$. frederiksenii within the larvae. The CFU of $Y$. frederiksenii increased from $1.15 \times 10^{3}$ to $3.21 \times 10^{3}$ (day one) and to $2.79 \times 10^{9}$ (day two) directly after the infection, and remained constant for next 3 days $\left(1.88-2.62 \times 10^{9}\right)$. This unimpeded bacterial growth resembles the mortality of the larvae that starts only when the Y. frederiksenii reaches its stationary phase. This finding suggests that a high cell number of this insect pathogen in the larvae of Galleria is a prerequisite for its toxicity and/or that the pathogen has incapacitated the host in the initial phase of intrahemocoelical infection.

We further reduced the infection dose to approximately 100-150 CFU and observed a slightly higher toxicity of $Y$. frederiksenii in comparison with $Y$. intermedia, which, however, started to kill larvae a day earlier (Figure 1B). In contrast, 145 CFU of Y. enterocolitica W22703 were not sufficient to kill any larva. Altogether, these data demonstrate a high, dose-dependent toxicity of $Y$. frederiksenii and $Y$. intermedia toward larvae of $G$. mellonella.

\section{Entomopathogenicity of $Y$. enterocolitica Strain 8081 Resembles That of $P$. luminescens}

We compared the injectable insecticidal activity of $P$. luminescens, Y. frederiksenii, Y. intermedia, and Y. enterocolitica strain 8081 (biotype 1B, serotype O:8), which carries a socalled "high-pathogenicity island" encoding the siderophore yersiniabactin (Carniel et al., 1996). In each experiment, the 
TABLE 1 | Oral infection of $M$. sexta and intrahemocoelic infection of G. mellonella for 5 days.

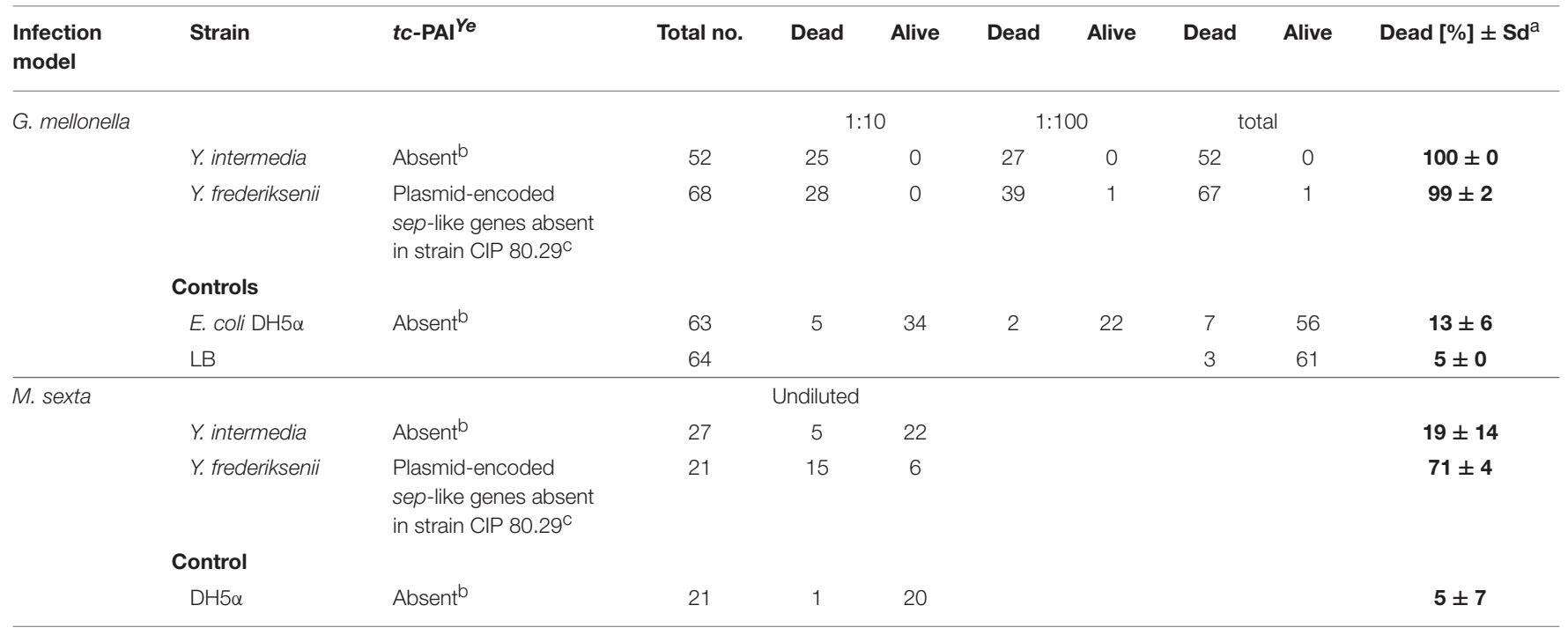

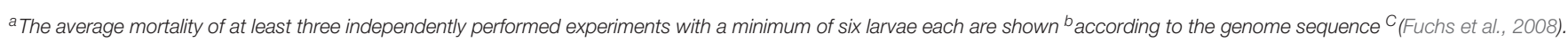
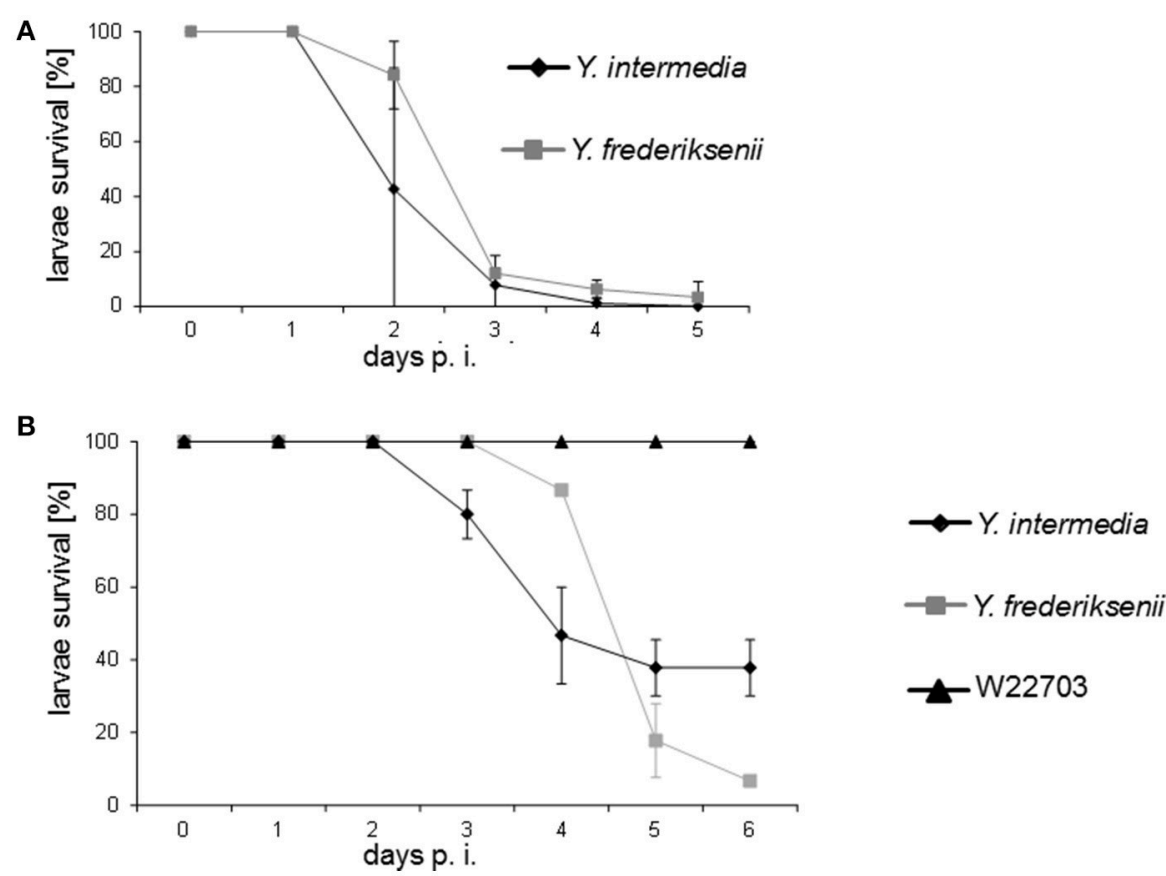

FIGURE 1 | Time course of G. mellonella infection assays with Y. frederiksenii and $Y$. intermedia. The strains were pregrown overnight at $30^{\circ} \mathrm{C}$, and the cultures were serially diluted. Aliquots of 5-7.5 $\mu \mathrm{l}$ from a $10^{4}$-fold or a $10^{5}$-fold dilution were used for infection, corresponding to (A) $1.44-5.50 \times 10^{3} \mathrm{Y}$. intermedia CFU and $1.43 \times$ $10^{3}-10^{4}$ Y. frederiksenii CFU, or (B) 120 Y. intermedia CFU, 95 Y. frederiksenii CFU, and 145 Y. enterocolitica W22703 CFU. Three independent experiments per strain were performed, with three groups composed of (A) 25, 29, and 30 larvae (Y. intermedia) and 20, 22, and 23 larvae (Y. frederiksenii), or (B) 15 larvae each. The larvae were incubated at $20^{\circ} \mathrm{C}$ and monitored daily. Error bars represent the standard error of the mean of three experiments.

lethality of the larvae decreased with lower numbers of CFU (Figure 2). Interestingly, the survival assays demonstrated that $Y$. enterocolitica 8081 is nearly as toxic as P. luminescens toward G. mellonella larvae upon intrahemocoelic infection, and is more virulent than $Y$. frederiksenii and $Y$. intermedia. Approximately $38 \mathrm{CFU}$ of $Y$. enterocolitica 8081 were revealed to be sufficient to kill nearly all larvae, after an infection period of 5 days. For comparison, larvae were intrahemocoelically infected with Y. enterocolitica W22703 and $\mathrm{DH} 5 \alpha$, demonstrating the high insect-pathogenicity of $Y$. frederiksenii, $Y$. intermedia, and $Y$. enterocolitica strain 8081 despite the lack of TC-PAI ${ }^{\mathrm{Ye}}$. Altogether, these data 


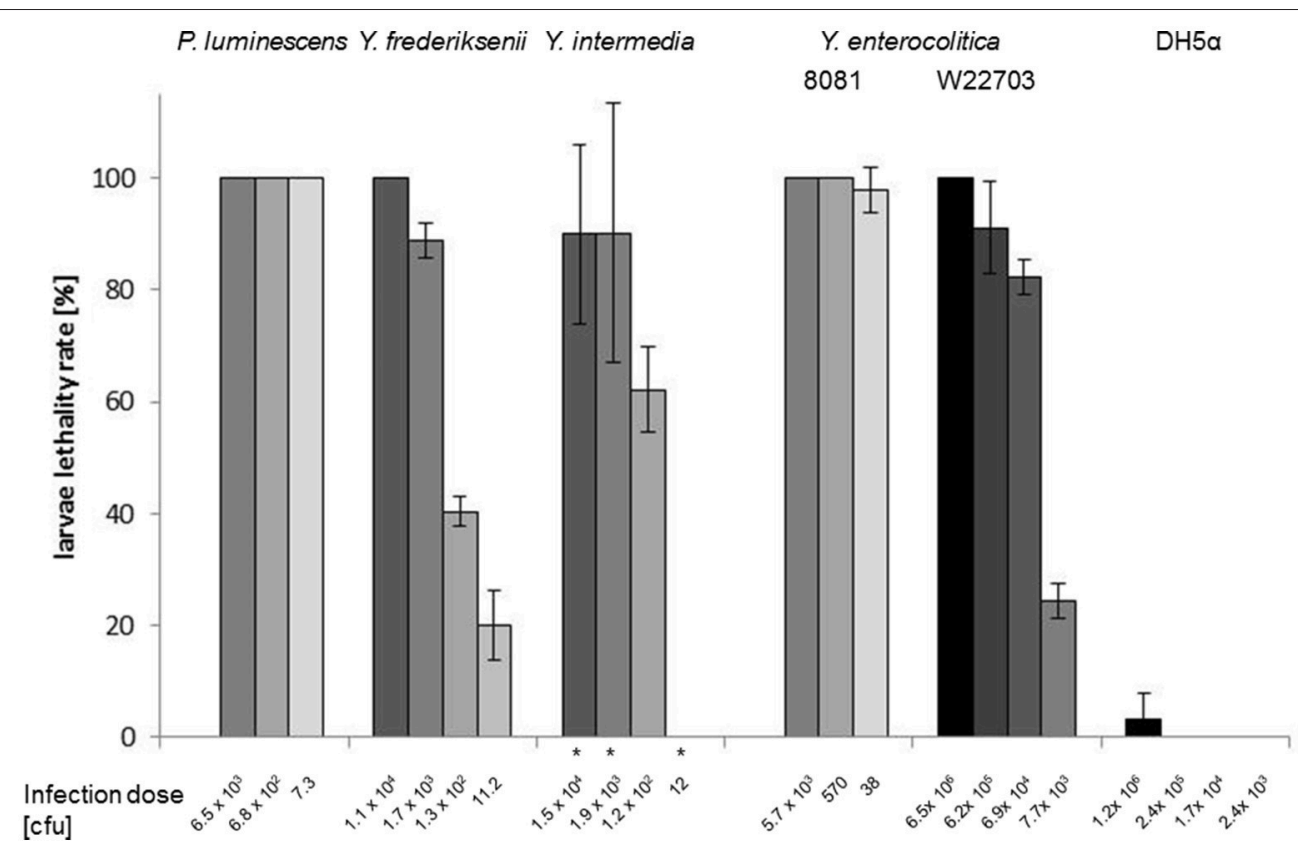

FIGURE 2 | Dose-dependent toxicity of Yersinia strains. Survival assays were performed by infection of G. mellonella larvae with $P$. luminescens, Y. frederiksenii, Y. intermedia, Y. enterocolitica 8081, Y. enterocolitica W22703, and E. coli DH5 $\alpha$. Infected larvae were incubated at $15^{\circ} \mathrm{C}$; few experiments $\left({ }^{\star}\right)$ were performed at $20^{\circ} \mathrm{C}$. The CFU used for the injection, the number of larvae, and the error bars (mean of experiments with three groups of larvae) are indicated. Groups of 15 larvae each were independently infected.

show that the lethality toward G. mellonella larvae is strictly dose-dependent.

\section{The Lethality of Yersinia Strains Is Temperature-Dependent}

Low temperature-dependent toxicity of Y. enterocolitica W22703 toward $M$. sexta and $C$. elegans, and of representative strains of $Y$. enterocolitica phylogroups 1-5 against $G$. mellonella has been reported previously (Bresolin et al., 2006; Fuchs et al., 2008; Spanier et al., 2010; Alenizi et al., 2016). Therefore, we tested whether the injectable insecticidal activity described earlier is higher at lower temperature. G. mellonella larvae were infected with varying cell numbers of $Y$. frederiksenii, $Y$. intermedia, $Y$. enterocolitica 8081, and Y. enterocolitica W22703 and incubated at $15^{\circ} \mathrm{C}$ and at $30^{\circ} \mathrm{C}$. However, upon infection with eight or 95 Y. frederiksenii $\mathrm{CFU}$, the larvae showed a higher survival rate at $30^{\circ} \mathrm{C}$ than at $15^{\circ} \mathrm{C}$ (Figure $3 \mathbf{A}$ ). A temperature-dependent pathogenicity toward G. mellonella was also observed for $Y$. intermedia. Although this species was found to be slightly low pathogenic at $15^{\circ} \mathrm{C}$ than $Y$. frederiksenii, we observed that at $30^{\circ} \mathrm{C}, 120 \mathrm{Y}$. intermedia CFU killed more larvae (40\% survival rate) in comparison with $95 \mathrm{Y}$. frederiksenii CFU (80\% survival rate) (Figure 3B). Y. enterocolitica 8081 exhibited a higher toxicity against the larvae at lower temperature as well. Only 57 $\mathrm{CFU}$ of this pathogen killed nearly all larvae at $15^{\circ} \mathrm{C}$, but $40 \mathrm{CFU}$ killed only $4 \%$ at $30^{\circ} \mathrm{C}$ (Figure 3C). Independent of the infection dose, Y. enterocolitica W22703 did not exhibit a significant temperature-dependent toxicity in this model (Figure 3D). A high infection dose of $9 \times 10^{5} \mathrm{CFU}$ quickly killed all larvae at $15^{\circ} \mathrm{C}$ and at $30^{\circ} \mathrm{C}$, and a low infection dose of $145 \mathrm{CFU}$ killed zero or only $7 \%$ of all larvae at these temperatures. Thus, a pronounced dose-dependent insecticidal activity was observed in these experiments with $Y$. frederiksenii, Y. intermedia, and both Y. enterocolitica strains.

\section{Phenotypes of Infected Larvae}

A healthy G. mellonella larva rapidly moves forward and back upon touch, and its exoskeleton is light colored. During the pathogenicity assays described earlier, we observed distinct phenotypes of the larvae at both $15^{\circ} \mathrm{C}$ and $30^{\circ} \mathrm{C}$ (Figure 4A). The insects infected with $95 \mathrm{Y}$. frederiksenii CFU were more agile at $30^{\circ} \mathrm{C}$, possibly due to the lower toxicity of the pathogen at this temperature. At this temperature, injuries by combats and thus the release of hemolymph is visible from day 3 post infectionem (p. i.) due to the high density of insects. From day 4 to $6 \mathrm{p}$. i., the number of insects in the pupal stage as well as cocoon production increased. At $15^{\circ} \mathrm{C}$, all larvae remained undamaged. However, their agility decreased from day 1 p. i. until the larvae moved only their heads or died. They also exhibited a stronger exoskeleton coloring from day $4 \mathrm{p}$. i. that strengthened until day 6 p. i. Furthermore, while non-infected larvae are sturdy, their body volume decreased upon the loss of liquid as visible in Figure 4B, left, on the larvae's surface.

Another interesting observation was the differential pigmentation of the larvae. Melanization is a defense mechanism of G. mellonella larvae to encapsulate pathogens, and the intensity of pigment formation correlates with the number of injected cells (Thomaz et al., 2013). Following infection with $Y$. 
A Y. frederiksenii

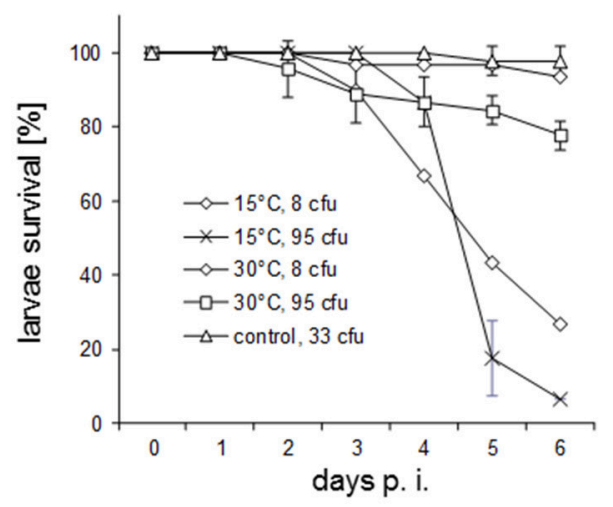

B

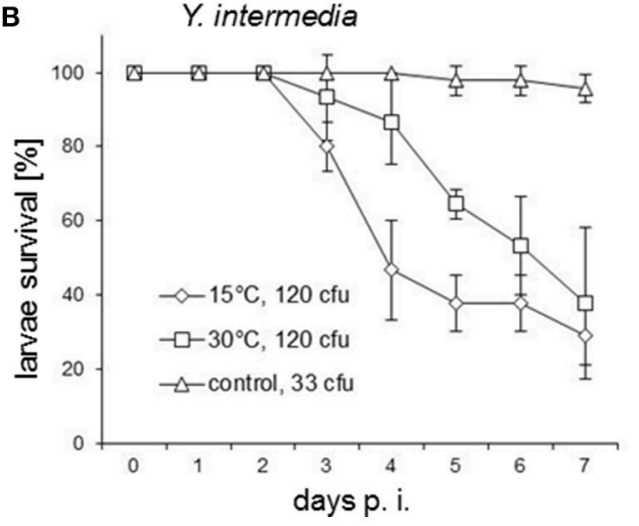

C

Y. enterocolitica 8081

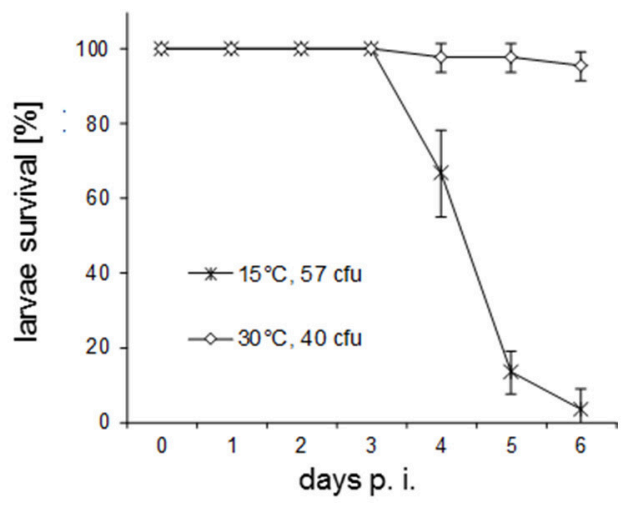

D

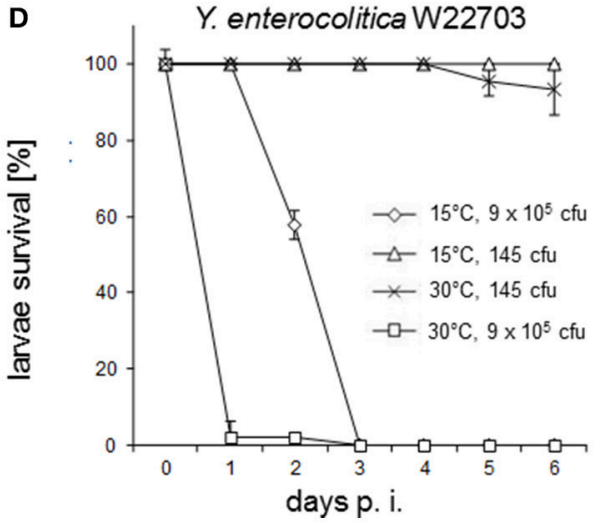

FIGURE 3 | Temperature-dependent pathogenicity of Yersinia strains against G. mellonella larvae. (A) Larvae were each infected with eight and 95 Y. frederiksenii $\mathrm{CFU}$, respectively, and incubated at $15^{\circ} \mathrm{C}$ and $30^{\circ} \mathrm{C}$; the experiment at $15^{\circ} \mathrm{C}$ with an infection dose of eight was performed with 30 ungrouped larvae. (B) Infection was done with $120 \mathrm{Y}$. intermedia CFU and the larvae incubated at $15^{\circ} \mathrm{C}$ and $30^{\circ} \mathrm{C}$. Infection with $\mathrm{E}$. coli $\mathrm{DH} 5 \alpha$ was used here as a control for all experiments. (C) 57 Y. enterocolitica $8081 \mathrm{CFU}$ were used to infect G. mellonella larvae, which were incubated at $15^{\circ} \mathrm{C}$; in a further assay, larvae infected with $40 \mathrm{CFU}$ were incubated at $30^{\circ} \mathrm{C}$; the experiment with an infection dose of $57 \mathrm{CFU}$ was done with $3 \times 10$ larvae. (D) Infection assays were performed with $9 \times 10^{5}$ or with $145 \mathrm{Y}$. enterocolitica W22703 CFU at $15^{\circ} \mathrm{C}$ and $30^{\circ} \mathrm{C}$. In all experiments, three groups of 15 larvae each were independently infected with the exceptions mentioned earlier. Error bars represent the standard deviations. The larvae survival rate was plotted against day's p. i.

frederiksenii and Y. intermedia, the larvae colored gray-brown to black before they died (Figure 4B); many larvae also exhibited a punctiform pigmentation that resembled that at the injection site. Larvae infected with $P$. luminescens, however, did not show such a pigmentation, but colored red, similar to the effect of red anthraquinones produced by $P$. luminescens following infection (Richardson et al., 1988). These observations point out to different factors that are involved in the injectable insecticidal activity of the three pathogens.

\section{A Genome Comparison Approach Identifies Potential Virulence Genes Present in Highly and Absent in Weakly Insecticidal Strains}

Although their genomes lack the $t c$ genes or their homologs, $Y$. intermedia and $Y$. frederiksenii are much more toxic against G. mellonella larvae than Y. enterocolitica W22703. This finding suggests the presence of yet unknown genetic determinants that contribute to the insecticidal activity of yersinia. Therefore, we performed a genome comparison that identified 329 genes that are common for Y. intermedia strain ATCC 29909 and Y. frederiksenii strain ATCC 33641, but absent in Y. enterocolitica W22703 (Table S1). This set comprises a large number of genes whose (putative) products belong to categories such as lipoproteins and other membrane proteins $(10+14)$, sensing, signaling, and regulation (36), metabolism (28), resistance toward toxic substances (17), transport and secretion $(16+12)$, stress response (2), and iron uptake and storage (9). With respect to genetic determinants potentially involved in pathogenicity, the bioinformatics approach identified putative adhesins, toxins, hemolysins, and secretory systems (Table 2). For example, $Y$. intermedia and $Y$. frederiksenii carry a type VI secretion system (T6SS) that, among other functions, contributes to virulence (Filloux, 2013) and is present in all Yersinia spp. and in $P$. luminescens, but not in Y. enterocolitica W22703. The two species harbor an ATP-binding protein possibly involved in uptake of heme, which is absent in all other species of the Yersinia genus, but closely related to a protein in Klebsiella pneumoniae. 

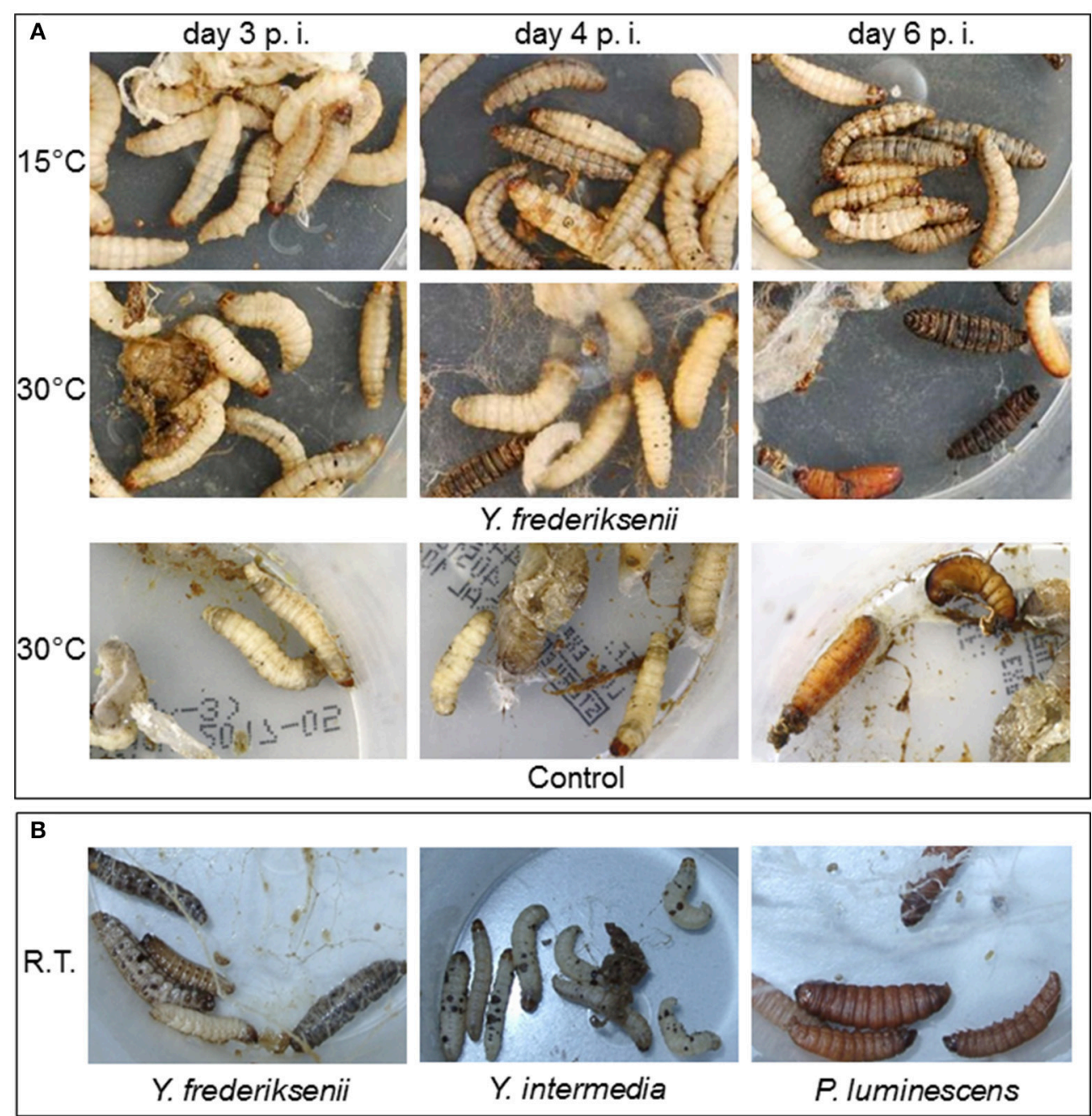

FIGURE 4 | Phenotypes of G. mellonella larvae after infection. (A) Larvae were infected with 95 Y. frederiksenii CFU, incubated at $15^{\circ} \mathrm{C}$ and $30^{\circ} \mathrm{C}$, and monitored until day 6 p. i.; larvae injected with $5 \mu$ l of LB medium served as control. (B) Infection was done with Y. frederiksenii (5 $\mu$ l of a $10^{3}$ dilution of an overnight culture), with $Y$. intermedia (5 $\mu \mathrm{l}$ of a $10^{4}$ dilution), and with P. luminescens (5 $\mu$ l of a $10^{4}$ dilution). Photographs were taken 3 days p. i. The larvae were incubated at room temperature (R.T.).

\section{Attenuated Insecticidal Phenotype of $Y$. frederiksenii $\triangle$ yacT}

In this genome comparison approach, we identified yacT (accession numbers EEQ13070 and WP_004712324) encoding a protein whose amino acid sequence exhibits a significant homology (e-value 0.0, identity 54\%; Supplementary Figure S1) to the heat-stable cytotonic enterotoxin (Ast) of Aeromonas hydrophila. We termed this protein, with a molecular weight of $71.46 \mathrm{kDa}$, Yersinia Ast-like cytotonic toxin (YacT), and the corresponding gene yacT. Homologs or orthologs of YacT are also encoded by $P$. luminescens, $P$. asymbiotica, and many Yersinia spp., but neither by Y. pestis or Y. pseudotuberculosis, nor by Y. enterocolitica strains W22703 and 8081. We generated a deletion mutant of yacT termed $Y$. frederiksenii $\Delta y a c T$, which was also complemented with pACYC-yacT carrying the toxin gene. On performing the G. mellonella infection assay at $15^{\circ} \mathrm{C}$, we observed a strongly reduced virulence of $Y$. frederiksenii $\Delta y a c T$ (time in days for $50 \%$ of the larvae to die, $\mathrm{TD}_{50}=5.4 \pm 0.22$ ) and of Y. frederiksenii $\Delta y a c T / \mathrm{pACYC} 184\left(\mathrm{TD}_{50}=5.59 \pm 0.01\right)$ in comparison to strain $Y$. frederiksenii/pACYC184 $\left(\mathrm{TD}_{50}=\right.$ $3.33 \pm 0.18$ ) (Table 3, Figure 5A). When the mutant harbored gene $y a c T$ in trans via plasmid pACYC-yacT, its phenotype reverted to that of the parental strain showing a $\mathrm{TD}_{50}=3.79$ \pm 0.46 . These data clearly demonstrated that yacT is required for the high virulence of $Y$. frederiksenii toward the larvae at $15^{\circ} \mathrm{C}$.

To understand better the role of the novel toxin during infection, the number of viable $Y$. frederiksenii cells within infected larvae incubated at $15^{\circ} \mathrm{C}$ was determined daily over a duration of 4 days (Figure 5B). We observed a strong growth of $Y$. frederiksenii within 4 days by more than six orders of magnitude. In comparison, a mutant $Y$. frederiksenii $\Delta y a c T$ 
TABLE 2 | Putative virulence factors of Y. frederiksenii and Y. intermedia absent in Y. enterocolitica W22703.

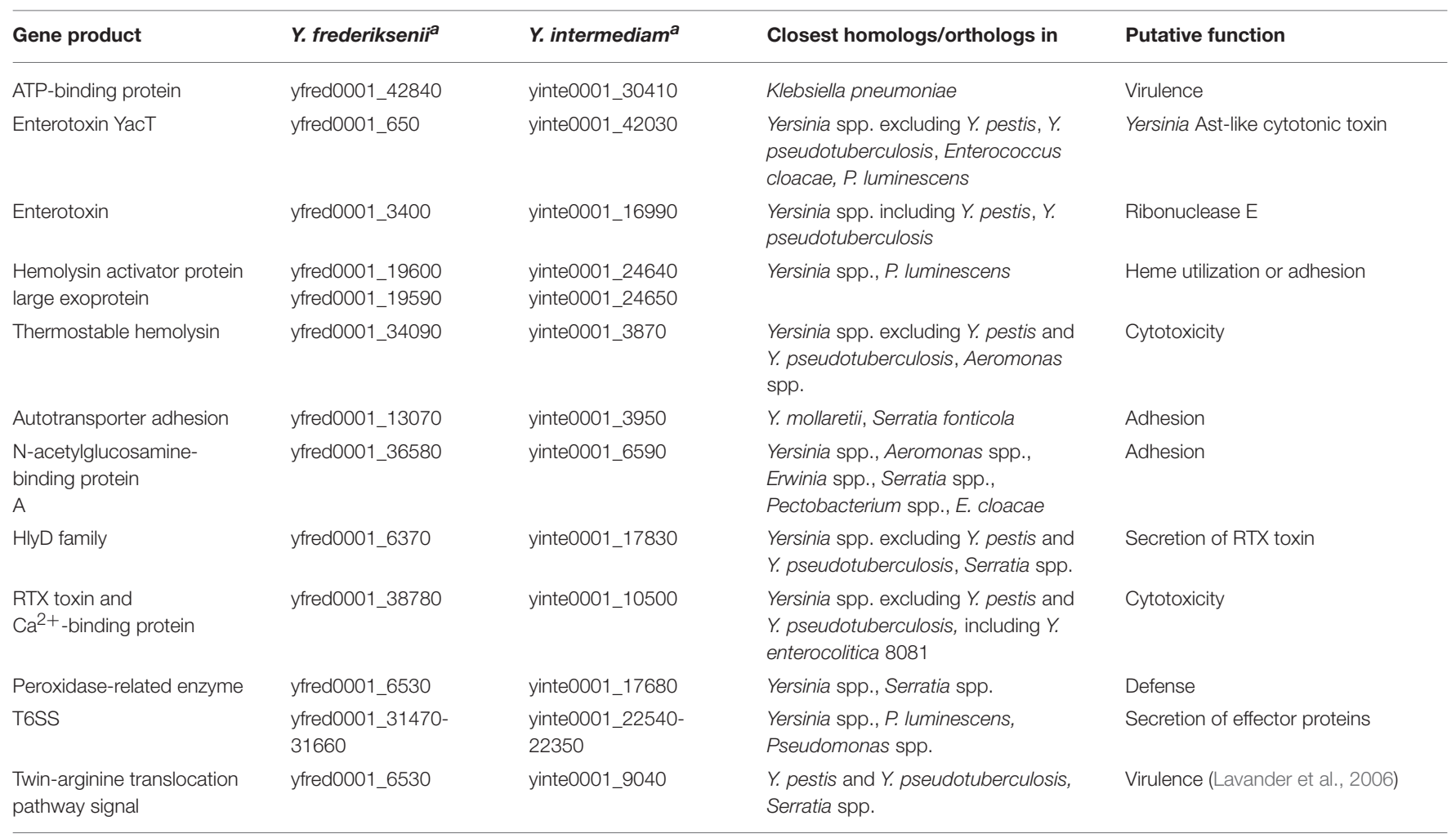

${ }^{a}$ Gene code was taken from the PEDANT 3 database (Walter et al., 2009).

TABLE 3 | Infection doses and $\mathrm{TD}_{50}$ values testing yacT.

CFU/ml inoculum

$$
\begin{aligned}
& 2.11 \times 10^{6} \pm 6.46 \times 10^{5} \\
& 2.63 \times 10^{6} \pm 3.05 \times 10^{5} \\
& 1.94 \times 10^{6} \pm 3.25 \times 10^{5} \\
& 2.72 \times 10^{6} \pm 5.12 \times 10^{5} \\
& 3.35 \times 10^{6} \pm 2.91 \times 10^{5} \\
& 24.11 \times 10^{6} \pm 7.50 \times 10^{5} \\
& 3.90 \times 10^{6} \pm 3.03 \times 10^{5} \\
& 3.15 \times 10^{6} \pm 1.91 \times 10^{5}
\end{aligned}
$$

CFU per $5 \mu \mathrm{I}$

$\mathrm{TD}_{50}{ }^{*}( \pm \mathrm{sd})$

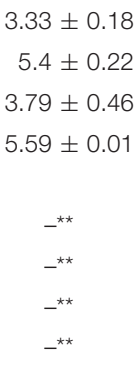

$1.05 \times 10^{4}$

$1.31 \times 10^{4}$

$9.70 \times 10^{3}$

$1.36 \times 10^{4}$

$1.68 \times 10^{4}$

$2.06 \times 10^{4}$

$1.95 \times 10^{4}$

$1.58 \times 10^{4}$

Sd, standard deviation; *, time in days for $50 \%$ of the larvae to die; **, more than $50 \%$ of the larvae survived.

exhibited a retarded proliferation at day 2 p. i., followed by growth stagnation for 1 day. However, at day 4 p. i., the mutant reached approximately the same cell density as the parental strain. These data confirm that the yersiniae cell numbers increase before the larvae start to die and that YacT contributes to proliferation of $Y$. frederiksenii within the insect host.

\section{Effect of YacT on Hemocytes}

YacT was purified from E. coli Bl21 (DE3)/pBAD-HisA(tet)-650. Six microliter of a toxin solution with a concentration of 1.4 $\mu \mathrm{g} / \mu \mathrm{l}$ or of phosphate-buffered saline (PBS) as control were injected into $20 \mathrm{G}$. mellonella larvae. The larvae of the toxin group showed paralysis of the half retral abdomen immediately after injection. In addition, some caterpillars of this group displayed a constriction of the head-thorax area and did not react to touching. In comparison, the control group showed none of these symptoms. One day p.i., animals of both groups that were kept at $30^{\circ} \mathrm{C}$ maintained vigor and formed fine webs. After web removal, 2 or 3 days p. i., the caterpillars of the toxin-treated group showed punctate- to strokelike black discolorations at the dorsal-abdominal areas that we did not observe in the control group (Supplementary Figure S2). 


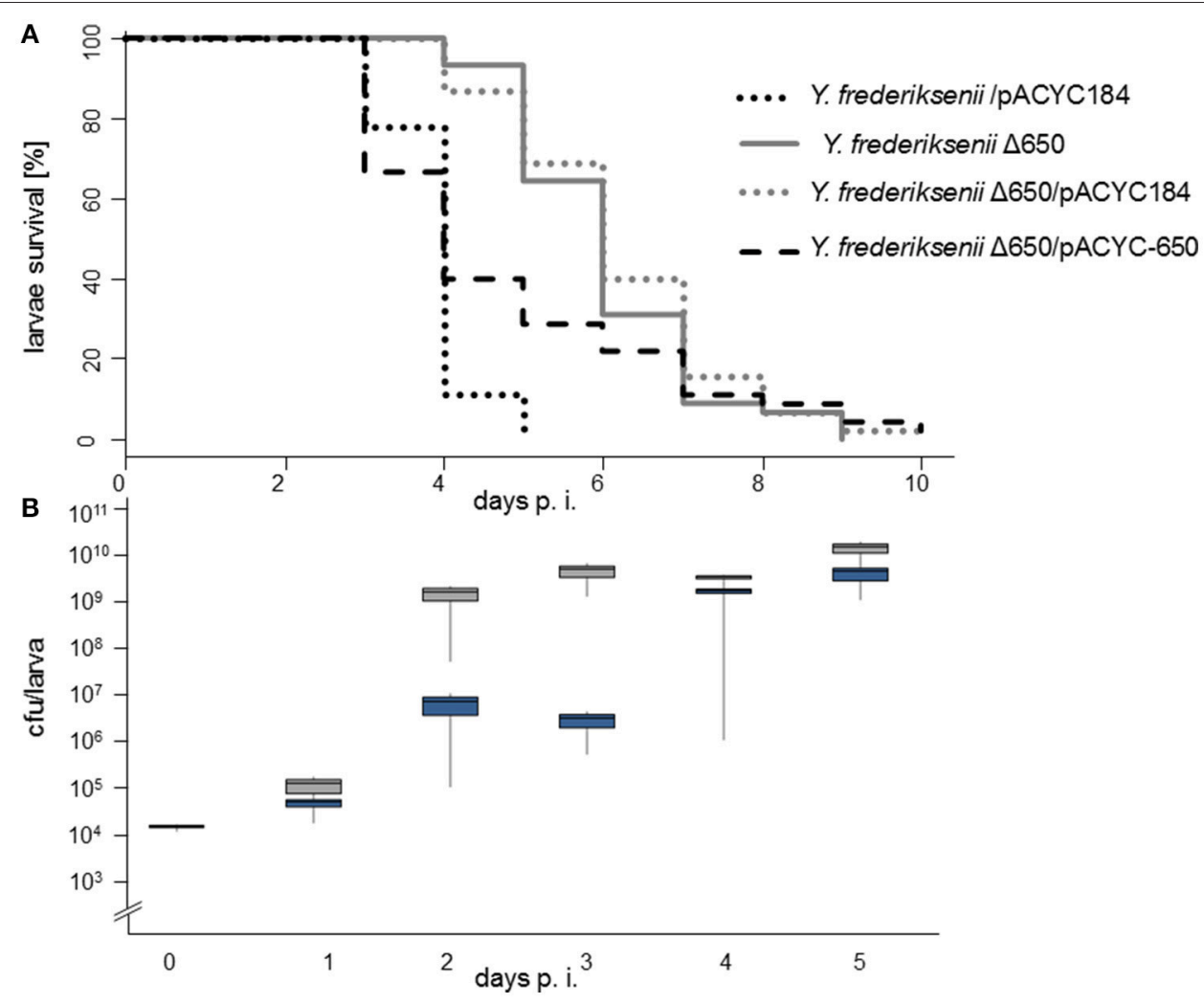

FIGURE 5 | Y. frederiksenii $\triangle y a c T$ exhibits attenuated virulence. (A) Y. frederiksenii/pACYC184, Y. frederiksenii $\triangle y a c T$, Y. frederiksenii $\triangle y a c T / p A C Y C 184$, and Y. frederiksenii $\triangle$ yacT /pACYC-yacT were used to infect G. mellonella larvae that were incubated for 10 days at $15^{\circ} \mathrm{C}$. Infection doses and $\mathrm{TD}_{50}$ values are indicated in Table 3. In all experiments depicted in the Kaplan-Meier plot, three independent infection experiments per strain were monitored, with groups composed of 15 larvae each. (B) Additionally, larvae infected in parallel were homogenized at the indicated time points and the number of viable Y. frederiksenii cells were enumerated. Gray boxes: Y. frederiksenii, black boxes: Y. frederiksenii $\Delta y a c T$. Standard deviations of three replicates are shown.

To study the effect of YacT on hemocytes after 1 day, the hemolymph of larvae was prepared from the aorta and streaked out on microscope slides for staining. Injection of PBS (10 mM phosphate buffer, $\mathrm{pH}$ 7.4; $2.7 \mathrm{mM} \mathrm{KCl} ; 137 \mathrm{mM} \mathrm{NaCl}$ ) served as a control. Upon microscopic analysis, we observed repeatedly several distinct cell phenotypes: hemocytes from animals treated with the toxin showed a round-shaped morphology and they began to form aggregates in comparison to the controls and several cells also enlarged and showed a reduction of chromatin, possibly indicating the beginning of early stages of the cell death (Figure 6A).

As a complementary experiment, G. mellonella larvae were infected orally with $Y$. frederiksenii and its yac $T$ deletion mutant. Again, the morphology and chromatin density of hemocytes were modified in the presence of $Y$. frederiksenii, but not of $Y$. frederiksenii $\Delta y a c T$ (Figure 6B). In both cases, yersinial cells were visible in the preparations, indicating that penetrating the gut epithelial barrier occurs independent of YacT.

\section{DISCUSSION}

Members of the genus Yersinia are fascinating organisms, as they are able to adapt to the environmental life cycle stage as well as to mammals (Fuchs et al., 2011). During a transition, they encounter a broad spectrum of hostile conditions, and a major clue to overcome these challenges is the temperature-dependent production of host-specific virulence factors. Therefore, the interaction of yersiniae with invertebrates may have been a precursor to human pathogenicity during evolution (Waterfield et al., 2004). In this study, we tested the entomopathogenic potential of a set of Yersinia spp. toward larvae of G. mellonella. The larvae are considered to be a natural host of yersiniae and other pathogens and, therefore, serve as an indicator of yersinial virulence activities against insects. We identified $Y$. enterocolitica 8081 , a representative of the highly pathogenic biovar $1 \mathrm{~B}$ group, to be the most virulent Yersinia strain tested so far against G. mellonella larvae, resembling the high insecticidal activity of $P$. luminescens. Data on strain 8081 as the least pathogenic strain among several $Y$. enterocolitica strains tested against $G$. Mellonella are not in contradiction with our findings, because Alenizi et al. performed the infection experiments at $25^{\circ} \mathrm{C}$ and missed the high toxicity at the environmental temperature of $15^{\circ} \mathrm{C}$ (Alenizi et al., 2016). Y. enterocolitica strain 5303, which belongs to the biovar 1A group and is considered to be apathogenic toward mammals, showed an even higher toxicity toward the Galleria larvae, since only ten CFU were sufficient 

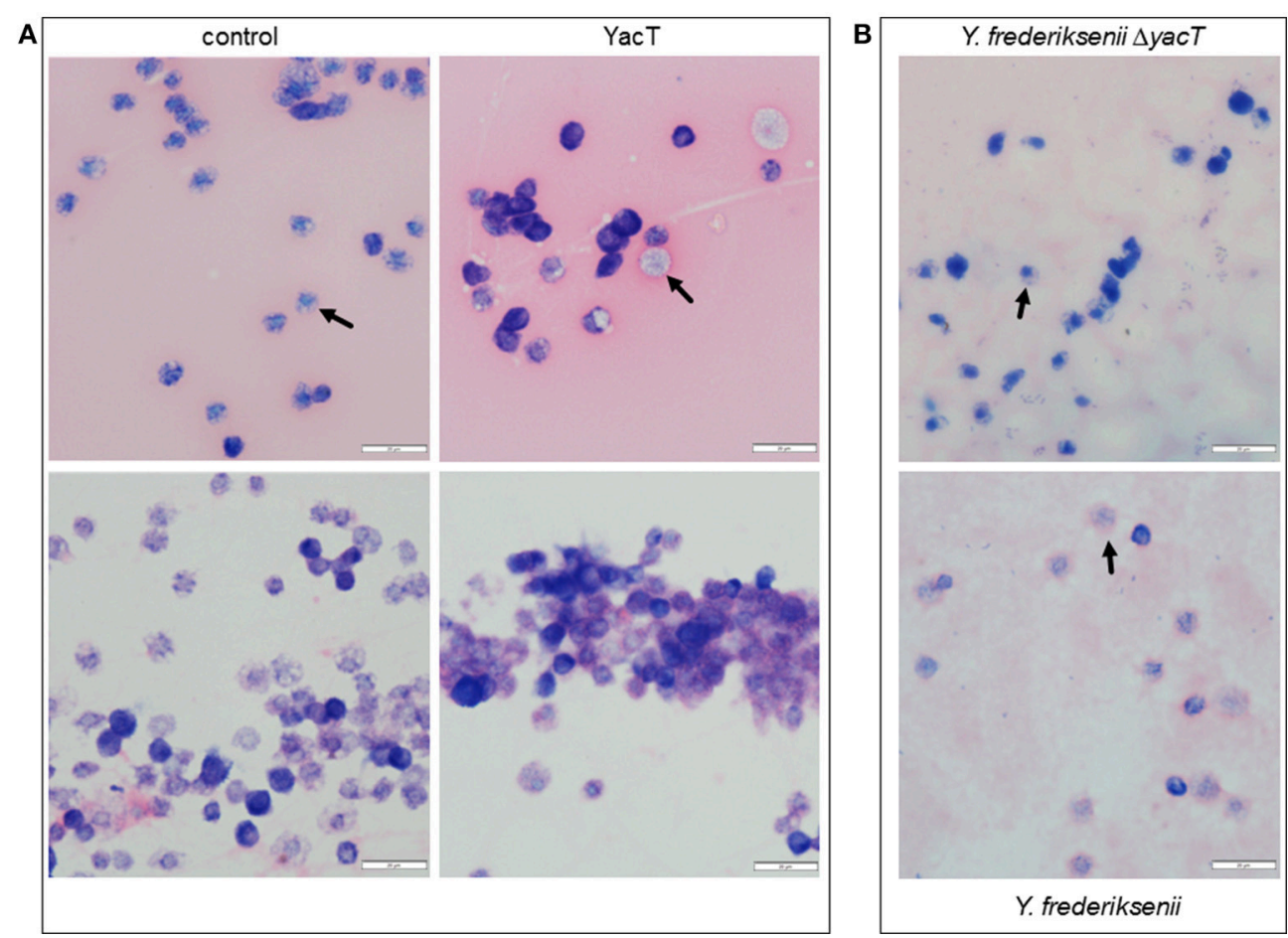

FIGURE 6 | Effect of purified YacT of Y. frederiksenii on hemocytes. (A) Six Microliter of purified YacT or of PBS (control) were injected. After 1 day, hemolymph preparations of G. mellonella larvae were fixed with methanol (upper row) or with aceton (lower row) and then stained by Giemsa solution. The hemocytes derived from YacT-treated larvae began to form some aggregates in comparison with controls (lower row). (B) Hemolymph preparations of larvae 1 day after oral infection with $6 \mu$ l of an overnight culture of Y. frederiksenii and Y. frederiksenii $\Delta y a c T$. Arrows point to changes of hemocyte morphology and chromatin density, the latter one as visible by the weaker nuclear staining. Photos of representative preparations are shown; the scale is indicated. Microscope Olympus BX53 was used with $600 \times$ magnification.

to kill $50 \%$ of the larvae within 5 days (Alenizi et al., 2016). Interestingly, also $Y$. intermedia and Y. frederiksenii are more virulent to Galleria larvae than other Yersinia spp., including $Y$. mollaretii, Y. bercovieri, Y. ruckeri, Y. aldovae, and Y. kristensenii, as tested recently (Fuchs et al., 2008). Y. frederiksenii and Y. intermedia occupy related ecological niches and exhibit very similar phenotypes (Martin et al., 2009). Y. intermedia, which is isolated mainly from the environment, animals, food, and (rarely) human beings, received its name due to its genetic and phenotypic properties that are an intermediate between those of $Y$. pseudotuberculosis and $Y$. enterocolitica (Martin et al., 2009). Y. intermedia also shares several $O$ antigens with Y. enterocolitica (Wauters et al., 1972), of which O:4 and O:17 are probably the prevailing serotypes (Ursing et al., 1980). Y. frederiksenii was differentiated from Y. enterocolitica in 1980 (Ursing et al., 1980). The high insecticidal potential might point out to yet overlooked natural habitats of these strains.

Temperature is an important signal in the regulation of yersinia virulence factors of that are predominantly produced at $37^{\circ} \mathrm{C}$ and repressed at temperatures lower than body temperature, or vice versa, as exemplified by the insecticidal tc genes in Y. enterocolitica W22703. Temperature-dependent mortality of $G$. mellonella upon oral infection, but not upon intrahemocoelic injection, was observed recently for $Y$. entomophaga (Hurst et al., 2015). Therefore, it is not a surprising outcome of this study that the toxicity of $Y$. frederiksenii, $Y$. intermedia, and $Y$. enterocolitica 8081 increases with lower temperature, thus pointing out to a relevant ecological niche of these strains. Irrespective of the fact that G. mellonella has been chosen here as an infection model rather than as a natural host for yersinial infection, the two temperatures applied here correspond to the lifestyle of $\mathrm{G}$. mellonella larvae that grow best between $29^{\circ} \mathrm{C}$ and $35^{\circ} \mathrm{C}$, and also develop at $15^{\circ} \mathrm{C}$, but not at $10^{\circ} \mathrm{C}$ or less.

The pronounced contrast between the insecticidal potential of $Y$. frederiksenii, Y. intermedia, and Y. enterocolitica 8081, on the one hand, and the TC-PAI ${ }^{Y e}$-harboring Y. enterocolitica W22703, on the other hand, at least with respect to the G.mellonella model used here, prompted us to perform a genome comparison. This approach aimed to identify the determinants that confer the high insecticidal activity of these strains. Table 2, which probably still lacks several factors involved in infection, points out to a broad spectrum of yersinial factors whose role in pathogenicity as well as their host specificity remains to be investigated. One of them is YacT that is highly homologous to the astencoded heat-stable, cytotonic enterotoxin of $A$. hydrophila (Chopra et al., 1994) that was associated with gastroenteritis 
and non-bloody diarrhea in children and shown to contribute to the fluid secretory response in a murine model (Sha et al., 2002). Cell lysates of $E$. coli cells carrying ast elongated Chinese hamster ovary cells, which is a typical response to enterotoxins (Chopra et al., 1994). Besides Yersinia strains, YacT orthologs were identified also in $P$. luminescens ssp. laumondii (e-value $\left.=10^{-177}\right)$ and in the human pathogen, $P$. asymbiotica $(e-$ value $=10^{-179}$ ), demonstrating that this factor is not unique to A. hydrophila as assumed previously (Sha et al., 2002). The prevalence of the Ast and YacT homologs confirms the strong functional relatedness between Photorhabdus spp. and Yersinia spp. with respect to their invertebrate and vertebrate association (Heermann and Fuchs, 2008). It is important to note that YacT is distinct from the heat-stable enterotoxin Yst of yersiniae, for which a homolog is missing in $Y$. frederiksenii ATCC 33641 and Y. intermedia (Singh and Virdi, 2004). Our data demonstrate that YacT is required for full pathogenicity toward G. mellonella. Moreover, the finding that YacT injection affects the morphology of hemocytes suggests that the immune response of G. mellonella controls better the proliferation of $Y$. frederiksenii $\Delta y a c T$ during the first 3 days p. i. as compared with that of $Y$. frederiksenii. The list of determinants in Table 3 and the variation of Yersinia spp. in pathogenesis toward Galleria larvae suggest that the yersinial toxicity toward insects upon intrahemocoelic infection is a multifactorial process due to the presence of several cytotoxic determinants. In the light of this assumption, the virulence attenuation upon deletion of yacT in Y. frederiksenii is remarkably high. Therefore, YacT is a candidate to explain the high toxicity of $Y$. frederiksenii against G. mellonella.

\section{CONCLUSION}

A major implication of this study is that the yersinial toxicity toward insects not only depends on the TC, but also on a broader set of insecticidal toxins than known so far. We identified a novel yersinial entomopathogenic factor, whose activity might be associated with the hemocoel rather than with the insect gut as indicated by the distinct oral and intrahemocoelic toxicity of $Y$. intermedia and $Y$. frederiksenii. The findings of this study and other studies suggest that yersiniae strains, regardless of being human pathogens or not, acquire a substantial selection advantage by entering invertebrates. By overcoming infection barriers such as the gut epithelium or the innate immune response of insect larvae or nematodes, they might bioconvert their host, thus getting easy access to energy- and nitrogenrich nutrients. The resulting proliferation increases the chance of Yersinia strains to be transmitted to other hosts including mammals.

\section{MATERIALS AND METHODS}

\section{Bacterial Strains and Growth Conditions}

The strains used in this study were Y. intermedia (Collection Institut Pasteur [CIP] 80.28; ATCC 29909), Y. frederiksenii (CIP 80.29; ATCC 33641), Y. enterocolitica 8081 (Virginia Miller, St. Louis, USA), Y. enterocolitica W22703 (Cornelis and Colson,
1975), and P. luminescens ssp. laumondii strain TT01 BX470251 (Fischer-Le Saux et al., 1999). All cultures were grown in lysogeny broth (LB) ( $10 \mathrm{~g} \mathrm{l}^{-1}$ tryptone, $5 \mathrm{~g} \mathrm{l}^{-1}$ yeast extract, and $5 \mathrm{~g} \mathrm{l}^{-1}$ $\mathrm{NaCl}$ ) or on lysogeny broth (LB) agar (LB broth supplemented with $1.5 \%$ w/v agar). Escherichia coli were grown at $37^{\circ} \mathrm{C}$ and $P$. luminescens and Yersinia strains at $30^{\circ} \mathrm{C}$. If appropriate, the media were supplemented with the following antibiotics: 50 $\mu \mathrm{g} \mathrm{ml}^{-1}$ streptomycin, $12 \mu \mathrm{g} \mathrm{ml}^{-1}$ tetracycline, $50 \mu \mathrm{g} \mathrm{ml}^{-1}$ kanamycin, $20 \mu \mathrm{g} \mathrm{ml}^{-1}$ chloramphenicol, and $20 \mu \mathrm{g} \mathrm{ml}$ nalidixic acid.

\section{General Molecular Techniques}

The DNA manipulation was performed according to standard procedures (Sambrook and Russell, 2001). To isolate the chromosomal DNA, $1.5 \mathrm{ml}$ of a bacterial culture was centrifuged, and the sediment was re-suspended in $400 \mu \mathrm{l}$ of lysis buffer ( $100 \mathrm{mM}$ Tris $\mathrm{pH} 8.0,5 \mathrm{mM}$ EDTA, $200 \mathrm{mM} \mathrm{NaCl}$ ). After incubation for $15 \mathrm{~min}$ on ice, $10 \mu \mathrm{l}$ of $10 \%$ SDS and $5 \mu \mathrm{l}$ of proteinase $\mathrm{K}(10 \mathrm{mg} / \mathrm{ml})$ were added, and the sample was incubated overnight at $55^{\circ} \mathrm{C}$. The chromosomal DNA was precipitated with $500 \mu$ l of isopropanol, washed in ethanol, dried, and dissolved in $500 \mu \mathrm{l}$ of TE buffer $(10 \mathrm{mM}$ Tris- $\mathrm{HCl}$, $1 \mathrm{mM} \mathrm{Na}{ }_{2}$ EDTA, pH 7.4) containing $1 \mu \mathrm{l}$ of RNase $(10 \mathrm{mg} / \mathrm{ml})$. Polymerase chain reactions (PCR) were carried out with Taq polymerase (Fermentas, Vilnius, and Lithunia) and the following programme: one cycle at $95^{\circ} \mathrm{C}$ for $2 \mathrm{~min} ; 30$ cycles at $95^{\circ} \mathrm{C}$ for $10 \mathrm{~s}$, at the appropriate annealing temperature for $30 \mathrm{~s}$, at $72^{\circ} \mathrm{C}$ for $45 \mathrm{~s}$ to $180 \mathrm{~s}$ depending on the expected fragment length; one cycle at $72^{\circ} \mathrm{C}$ for $10 \mathrm{~min}$. Four Microliter of chromosomal DNA (100 $\mathrm{ng} \mathrm{m}^{-1}$ ) was used as a template for PCR amplification, and the GeneRuler DNA mix (Fermentas) served as a DNA ladder.

\section{Genome Comparison}

The sequences of genome used for the comparison were that of Y. enterocolitica 8081 (accession numbers AM286415 for the chromosome and AM286416 for the plasmid), Y. intermedia (genome draft: GCA_000168035.1), and Y. frederiksenii (genome draft: GCA_000754805.1). Homology searches of predicted proteins were performed by basic local alignment search tool analysis (Altschul et al., 1997). The PEDANT software system [http://pedant.gsf.de; (Walter et al., 2009)] was used for automatic genome sequence analysis and annotation (Frishman et al., 2001). Genomes were recorded and homology searches of predicted proteins were performed by SIMAP (Arnold et al., 2014). The genome comparisons were calculated by using a custom Perl script, which formatted bidirectional-best sequence hits between all predicted proteins $(E \leq 0.0001)$.

\section{Insecticidal Bioassays}

M. sexta were reared as described (Schachtner et al., 2004). For oral bioassays, bacteria were grown at $15^{\circ} \mathrm{C}$ (Yersinia strains) or $37^{\circ} \mathrm{C}(\mathrm{DH} 5 \alpha)$ until stationary phase. About $50 \mu \mathrm{l}$ of a culture was applied to $4 \mathrm{~mm}^{3}$ disks of an agar-based artificial diet (David and Gardiner, 1965). The liquid was allowed to soak into the agar block, which was dried under a laminar flow. First-instar M. sexta neonate larvae were placed on the disk and incubated at $22^{\circ} \mathrm{C}$. 
The application of bacterial culture aliquots was repeated after 3 days, and the larvae mortality was recorded after 5 days.

Larvae of G. mellonella were obtained from the ZooFachmarkt (München, Germany) and stored for less than 1 week at room temperature. Bacterial strains were grown to stationary phase (optical density at $600 \mathrm{~nm}\left[\mathrm{OD}_{600}\right] \sim 1-5 \times 10^{9} \mathrm{cfu} / \mathrm{ml}$ ) at temperatures between $15^{\circ} \mathrm{C}$ and $30^{\circ} \mathrm{C}$ (Yersinia spp.), at $30^{\circ} \mathrm{C}$ (P. luminescens), or at $37^{\circ} \mathrm{C}(\mathrm{DH} 5 \alpha)$, and 10 -fold serial diluted. Larvae of 2-3 cm length and of $110-130 \mathrm{mg}$ weight were used. A $5 \mu \mathrm{l}$ of the bacterial culture or an appropriate dilution thereof were orally applied or injected by a sterilized microsyringe (Hamilton $1702 \mathrm{RN}, 25 \mu \mathrm{l}$ ) into the hemocoel through the last left proleg. The aperture reseals after the removal of the syringe, thus preventing the loss of inoculum (Kavanagh and Reeves, 2004).

Infection doses were determined by plating serial dilutions of the cultures used for injection. Control assays had demonstrated that neither the medium nor the wounding by the syringe contributes to the mortality rate of the insects (Fuchs et al., 2008). Infected larvae were incubated for at least 5 days in the dark at the temperature indicated and the number of killed and alive larvae were enumerated each day. Larvae were considered dead if they failed to respond to touch. The $\mathrm{TD}_{50}$ was calculated using the dose-response curve ( $\mathrm{drc}$ ) package of the $\mathrm{R}$ software. To recover bacteria from the larvae, the larvae were surface sterilized with $70 \%$ ethanol, washed in $\mathrm{H}_{2} \mathrm{O}$, and cut into small pieces. The homogenous mass was suspended into $1 \mathrm{ml} \mathrm{LB}$, rigorously shaken for $5 \mathrm{~min}$ with a vortex, and centrifuged at 1,000 rpm for $2 \mathrm{~min}$. Serial dilutions were plated on agar plates with LB or with Yersinia selective medium (Schiemann CIN medium, Oxoid, Wesel, Germany).

\section{Deletion Mutants and Complementing Plasmid}

In-frame deletion of yacT from $Y$. frederiksenii was performed by the one-step method based on the phage $\lambda$ Red recombinase (Datsenko and Wanner, 2000). In short, PCR products comprising the kanamycin resistance cassette of plasmid pKD4, including the flanking FRT sites, were generated using pairs of 70 -nucleotide-long primers that included 20 nucleotides priming sequences for pKD4 as template DNA. Homology extensions of 50 bp overlapped 18 nucleotides of the $5^{\prime}$-end and 36 nucleotides of the $3^{\prime}$-end of the target gene (Link et al., 1997). About 500$1,000 \mathrm{ng}$ of fragment DNA were transferred into $Y$. frederiksenii cells harboring plasmid pKD119. Allelic replacement of the target gene by the kanamycin resistance cassette was controlled by PCR, and nonpolar deletion mutants were obtained via transformation of pCP20. The deletion was confirmed by PCR and sequencing.

Gene yacT including 220 bp upstream and 100 bp downstream of the coding sequence was amplified with the oligonucleotides 5 -CGATGAATTCAGTGACCGTCTGTG GGTCTG-3' and 5'-CGGCCATGGGGGGGCAGCATCGTG GATTC-3' and ligated into the chloramphenicol resistance cassette of plasmid pACYC184 via NcoI und EcoRI, resulting in pACYC-yacT. The recombinant plasmid was validated by PCR and sequencing.

\section{Overproduction and Purification of YacT}

Gene yacT of $Y$. frederiksenii was cloned into plasmid pBADHisA(tet) (Starke et al., 2013) via SacI and PstI using the oligonucleotides 5' -CGATGAGCTCATGCAGAAAATCATACC GAG-3' and 5'-AACTGCAGTTATTGGGTGCTAGCCACAG$3^{\prime}$. An overnight culture of E. coli $\mathrm{Bl} 21$ (DE3)/pBADHisA(tet)-650 was diluted $1: 100$ into $800 \mathrm{ml}$ of $\mathrm{LB}$ medium supplemented with $12 \mu \mathrm{g} / \mathrm{ml}$ tetracycline and incubated at $37^{\circ} \mathrm{C}$ with rotation at $180 \mathrm{rpm}$. At an $\mathrm{OD}_{600}$ of 0.6 , protein production was induced by adding $0.2 \%$ of arabinose. After incubation for an additional $4 \mathrm{~h}$ at $37^{\circ} \mathrm{C}$ and $180 \mathrm{rpm}$, the cells were harvested by centrifugation at $4^{\circ} \mathrm{C}$ and $7,500 \mathrm{rpm}$ for $20 \mathrm{~min}$. The pellets were each re-suspended in $5 \mathrm{ml}$ of native lysis buffer $\left(50 \mathrm{mM} \mathrm{NaH} \mathrm{PO}_{4}, 300 \mathrm{mM} \mathrm{NaCl}\right.$, and $10 \mathrm{mM}$ imidazole at $\mathrm{pH} 8.0$ ) in the presence of $1 \mathrm{mM}$ protease inhibitor Pefabloc SC (Sigma-Aldrich, Taufkirchen, Germany) and lysed by 4 passages through a French press (SLM Aminca Instruments, Rochester, NY, USA) at 900 psi; residual cell debris was removed thrice by centrifugation at $4^{\circ} \mathrm{C}$ and 9,000 rpm for $15 \mathrm{~min}$. Following the filtration, YacT was isolated using the Ni-NTA Fast Start Kit (Qiagen, Hilden, Germany) according to the manufacturer's instructions. For imidazole removal, proteins were dialyzed against $50 \mathrm{mM}$ phosphate buffer plus $0.5 \mathrm{mM} \mathrm{MgSO}_{4}, 0.5 \mathrm{mM} \mathrm{ZnSO}_{4}$, and $0.5 \mathrm{mM} \mathrm{CaCl}_{2}$ and protein extracts were concentrated down to $1 \mathrm{ml}$ with Amicon ultracentrifugal filter units (Millipore). The protein concentration was determined using Roti-Quant solution (Carl, Roth $\mathrm{GmbH}$, Karlsruhe, Germany) according to the Bradford method (Bradford, 1976). The purity of the eluted fractions was analyzed by the separation on a $12.5 \%$ sodium dodecyl sulfate (SDS)-PAA gel (Supplementary Figure S3).

\section{AUTHOR CONTRIBUTIONS}

KS, P-AS, and CM performed infection assays and analyzed the results, AF constructed the recombinant strains, TR was responsible for the genome comparison, and TF analyzed the data, conceived the study, and wrote the manuscript. All authors drafted and revised the work and approved of the final version.

\section{ACKNOWLEDGMENTS}

We thank Siegfried Scherer for supporting this study, Luise Ernst for technical assistance, Elisabeth Liebler-Tenorio for support in microscopical analysis, and Henry Derschum, Virginia Miller, Guy Cornelis, and Ralf Heermann for the gift of strains. This study was supported by a grant from the Deutsche Forschungsgemeinschaft (DFG) to TF (FU375/4-2).

\section{SUPPLEMENTARY MATERIAL}

The Supplementary Material for this article can be found online at: https://www.frontiersin.org/articles/10.3389/fcimb. 2018.00392/full\#supplementary-material 


\section{REFERENCES}

Alenizi, D., Ringwood, T., Redhwan, A., Bouraha, B., Wren, B. W., Prentice, M., et al. (2016). All Yersinia enterocolitica are pathogenic: virulence of phylogroup 1 Y. enterocolitica in a Galleria mellonella infection model. Microbiology 162, 1379-1387. doi: 10.1099/mic.0.000311

Altschul, S. F., Madden, T. L., Schaffer, A. A., Zhang, J., Zhang, Z., Miller, W., et al. (1997). Gapped BLAST and PSI-BLAST: a new generation of protein database search programs. Nucleic Acids Res. 25, 3389-3402. doi: 10.1093/nar/25.17.3389

Arnold, R., Goldenberg, F., Mewes, H. W., and Rattei, T. (2014). SIMAPthe database of all-against-all protein sequence similarities and annotations with new interfaces and increased coverage. Nucleic Acids Res. 42, 279-284. doi: 10.1093/nar/gkt970

Bishop, A. H. (2014). Expression of prtA from Photorhabdus luminescens in Bacillus thuringiensis enhances mortality in lepidopteran larvae by sub-cutaneous but not oral infection. J. Invertebr. Pathol. 121, 85-88. doi: 10.1016/j.jip.2014.07.001

Bradford, M. M. (1976). A rapid and sensitive method for the quantitation of microgram quantities of protein utilizing the principle of protein-dye binding. Anal. Biochem. 72, 248-254. doi: 10.1016/0003-2697(76)90527-3

Bresolin, G., Morgan, J. A., Ilgen, D., Scherer, S., and Fuchs, T. M. (2006). Low temperature-induced insecticidal activity of Yersinia enterocolitica. Mol. Microbiol. 59, 503-512. doi: 10.1111/j.1365-2958.2005.04916.x

Brown, S. E., Cao, A. T., Dobson, P., Hines, E. R., Akhurst, R. J., and East, P. D. (2006). Txp40, a ubiquitous insecticidal toxin protein from Xenorhabdus and Photorhabdus bacteria. Appl. Environ. Microbiol. 72, 1653-1662. doi: 10.1128/AEM.72.2.1653-1662.2006

Busby, J. N., Landsberg, M. J., Simpson, R. M., Jones, S. A., Hankamer, B., Hurst, M. R., et al. (2012). Structural analysis of Chil Chitinase from Yen-Tc: the multisubunit insecticidal ABC toxin complex of Yersinia entomophaga. J. Mol. Biol. 415, 359-371. doi: 10.1016/j.jmb.2011.11.018

Carniel, E., Guilvout, I., and Prentice, M. (1996). Characterization of a large chromosomal "high-pathogenicity island" in biotype 1B Yersinia enterocolitica. J. Bacteriol. 178, 6743-6751. doi: 10.1128/jb.178.23.6743-6751.1996

Chopra, A. K., Pham, R., and Houston, C. W. (1994). Cloning and expression of putative cytotonic enterotoxin-encoding genes from Aeromonas hydrophila. Gene 139, 87-91. doi: 10.1016/0378-1119(94)90528-2

Cornelis, G., and Colson, C. (1975). Restriction of DNA in Yersinia enterocolitica detected by recipient ability for a derepressed R factor from Escherichia coli. J. Gen. Microbiol. 87, 285-291. doi: 10.1099/00221287-87-2-285

Daborn, P. J., Waterfield, N., Silva, C. P., Au, C. P., Sharma, S., and FfrenchConstant, R. H. (2002). A single Photorhabdus gene, makes caterpillars floppy ( $m c f$ ), allows Escherichia coli to persist within and kill insects. Proc. Natl. Acad. Sci. U.S.A. 99, 10742-10747. doi: 10.1073/pnas.102068099

Datsenko, K. A., and Wanner, B. L. (2000). One-step inactivation of chromosomal genes in Escherichia coli K-12 using PCR products. Proc Natl Acad Sci USA. 97, 6640-6645. doi: 10.1073/pnas.120163297

David, W. A. L., and Gardiner, B. O. C. (1965). Rearing Pieris brassicae larvae on a semi-synthetic diet. Nature 207, 882-883. doi: 10.1038/207882b0

ffrench-Constant, R. H., Dowling, A., and Waterfield, N. R. (2007). Insecticidal toxins from Photorhabdus bacteria and their potential use in agriculture. Toxicon 49, 436-451. doi: 10.1016/j.toxicon.2006.11.019

Filloux, A. (2013). The rise of the Type VI secretion system. F1000Prime Rep. 5:52. doi: 10.12703/P5-52

Fischer-Le Saux, M., Viallard, V., Brunel, B., Normand, P., and Boemare, N. E. (1999). Polyphasic classification of the genus Photorhabdus and proposal of new taxa: $P$. luminescens subsp. luminescens subsp. nov., $P$. luminescens subsp. akhurstii subsp. nov., $P$. luminescens subsp. laumondii subsp. nov., $P$. temperata sp. nov., P. temperata subsp. temperata subsp. nov. and P. asymbiotica sp. nov. Int. J. Syst. Bacteriol. 49, 1645-1656. doi: 10.1099/00207713-494-1645

Frishman, D., Albermann, K., Hani, J., Heumann, K., Metanomski, A., Zollner, A., et al. (2001). Functional and structural genomics using PEDANT. Bioinformatics 17, 44-57. doi: 10.1093/bioinformatics/17.1.44

Fuchs, T. M., Brandt, K., Starke, M., and Rattei, T. (2011). Shotgun sequencing of Yersinia enterocolitica strain W22703 (biotype 2, serotype O:9): genomic evidence for oscillation between invertebrates and mammals. BMC Genomics 12:168. doi: $10.1186 / 1471-2164-12-168$
Fuchs, T. M., Bresolin, G., Marcinowski, L., Schachtner, J., and Scherer, S. (2008). Insecticidal genes of Yersinia spp.: taxonomical distribution, contribution to toxicity towards Manduca sexta and Galleria mellonella, and evolution. BMC Microbiol. 8:214. doi: 10.1186/1471-2180-8-214

Heermann, R., and Fuchs, T. M. (2008). Comparative analysis of the Photorhabdus luminescens and the Yersinia enterocolitica genomes: uncovering candidate genes involved in insect pathogenicity. BMC Genomics 9:40. doi: 10.1186/1471-2164-9-40

Hurst, M. R., Beattie, A. K., Jones, S. A., Hsu, P. C., Calder, J., and Van Koten, C. (2015). Temperature-Dependent Galleria mellonella mortality as a result of Yersinia entomophaga infection. Appl. Environ. Microbiol. 81, 6404-6414. doi: 10.1128/AEM.00790-15

Hurst, M. R., Becher, S. A., Young, S. D., Nelson, T. L., and Glare, T. R. (2010). Yersinia entomophaga sp. nov. isolated from the New Zealand grass grub Costelytra zealandica. Int. J. Syst. Evol. Microbiol. 61, 844-849. doi: $10.1099 /$ ijs.0.024406-0

Hurst, M. R., Jones, S. A., Binglin, T., Harper, L. A., Jackson, T. A., and Glare, T. R. (2011). The main virulence determinant of Yersinia entomophaga MH96 is a broad-host-range toxin complex active against insects. J. Bacteriol. 193, 1966-1980. doi: 10.1128/JB.01044-10

Kavanagh, K., and Reeves, E. P. (2004). Exploiting the potential of insects for in vivo pathogenicity testing of microbial pathogens. FEMS Microbiol. Rev. 28, 101-112. doi: 10.1016/j.femsre.2003.09.002

Lavander, M., Ericsson, S. K., Broms, J. E., and Forsberg, A. (2006). The twin arginine translocation system is essential for virulence of Yersinia pseudotuberculosis. Infect. Immun. 74, 1768-1776. doi: 10.1128/IAI.74.3.1768-1776.2006

Link, A. J., Phillips, D., and Church, G. M. (1997). Methods for generating precise deletions and insertions in the genome of wild-type Escherichia coli: application to open reading frame characterization. J. Bacteriol. 179, 6228-6237. doi: 10.1128/jb.179.20.6228-6237.1997

Marceau, M. (2005). Transcriptional regulation in Yersinia: an update. Curr. Issues Mol. Biol. 7, 151-177.

Martin, L., Leclercq, A., Savin, C., and Carniel, E. (2009). Characterization of atypical isolates of Yersinia intermedia and definition of two new biotypes. J. Clin. Microbiol. 47, 2377-2380. doi: 10.1128/JCM.02512-08

Merhej, V., Adekambi, T., Pagnier, I., Raoult, D., and Drancourt, M. (2008). Yersinia massiliensis sp. nov., isolated from fresh water. Int. J. Syst. Evol. Microbiol. 58, 779-784. doi: 10.1099/ijs.0.65219-0

Murros-Kontiainen, A. E., Fredriksson-Ahomaa, M., Korkeala, H., Johansson, P., Rahkila, R., and Bjorkroth, J. (2010a). Yersinia nurmii sp. nov. Int. J. Syst. Evol. Microbiol. 61, 2368-2372. doi: 10.1099/ijs.0.024836-0

Murros-Kontiainen, A. E., Johansson, P., Niskanen, T., Fredriksson-Ahomaa, M., Korkeala, H., and Bjorkroth, J. (2010b). Yersinia pekkanenii sp. nov. Int. J. Syst. Evol. Microbiol. 61, 2363-2367. doi: 10.1099/ijs.0.019984-0

Richardson, W. H., Schmidt, T. M., and Nealson, K. H. (1988). Identification of an anthraquinone pigment and a hydroxystilbene antibiotic from Xenorhabdus luminescens. Appl. Environ. Microbiol. 54, 1602-1605.

Sambrook, J., and Russell, D. W. (2001). Molecular Cloning: A Laboratory Manual, $3 r d E d n$. Cold Spring Harbor, NY: Cold Spring Harbor Laboratory.

Savin, C., Martin, L., Bouchier, C., Filali, S., Chenau, J., Zhou, Z., et al. (2014). The Yersinia pseudotuberculosis complex: characterization and delineation of a new species, Yersinia wautersii. Int. J. Med. Microbiol. 304, 452-463. doi: 10.1016/j.ijmm.2014.02.002

Schachtner, J., Huetteroth, W., Nighorn, A., and Honegger, H. W. (2004). Copper/zinc superoxide dismutase-like immunoreactivity in the metamorphosing brain of the sphinx moth Manduca sexta. J. Comp. Neurol. 469, 141-152. doi: 10.1002/cne.10992

Sha, J., Kozlova, E. V., and Chopra, A. K. (2002). Role of various enterotoxins in Aeromonas hydrophila-induced gastroenteritis: generation of enterotoxin genedeficient mutants and evaluation of their enterotoxic activity. Infect. Immun. 70, 1924-1935. doi: 10.1128/IAI.70.4.1924-1935.2002

Singh, I., and Virdi, J. S. (2004). Production of Yersinia stable toxin (YST) and distribution of $y$ st genes in biotype 1A strains of Yersinia enterocolitica. J. Med. Microbiol. 53, 1065-1068. doi: 10.1099/jmm.0.45527-0

Spanier, B., Starke, M., Higel, F., Scherer, S., and Fuchs, T. M. (2010). Yersinia enterocolitica infection and tcaA-dependent killing of Caenorhabditis elegans. Appl. Environ. Microbiol. 76, 6277-6285. doi: 10.1128/AEM.01274-10 
Sprague, L. D., and Neubauer, H. (2005). Yersinia aleksiciae sp. nov. Int. J. Syst. Evol. Microbiol. 55, 831-835. doi: 10.1099/ijs.0.63220-0

Sprague, L. D., Scholz, H. C., Amann, S., Busse, H. J., and Neubauer, H. (2008). Yersinia similis sp. nov. Int. J. Syst. Evol. Microbiol. 58, 952-958. doi: 10.1099/ijs.0.65417-0

Starke, M., and Fuchs, T. M. (2014). YmoA negatively controls the expression of insecticidal genes in Yersinia enterocolitica. Mol. Microbiol. 92, 287-301. doi: $10.1111 / \mathrm{mmi} .12554$

Starke, M., Richter, M., and Fuchs, T. M. (2013). The insecticidal toxin genes of Yersinia enterocolitica are activated by the thermolabile LTTRlike regulator TcaR2 at low temperatures. Mol. Microbiol. 89, 596-611. doi: $10.1111 / \mathrm{mmi} .12296$

Sulakvelidze, A. (2000). Yersiniae other than $Y$. enterocolitica, $Y$. pseudotuberculosis, and Y. pestis: the ignored species. Microbes Infect. 2, 497-513. doi: 10.1016/S1286-4579(00)00311-7

Thomaz, L., Garcia-Rodas, R., Guimaraes, A. J., Taborda, C. P., Zaragoza, O., and Nosanchuk, J. D. (2013). Galleria mellonella as a model host to study Paracoccidioides lutzii and Histoplasma capsulatum. Virulence 4, 139-146. doi: 10.4161/viru. 23047

Ursing, J., Brenner, D. J., Bercovier, H., Fanning, G. R., Steigerwalt, A. G., Brault, J., et al. (1980). Yersinia frederiksenii: a new species of Enterobacteriaceae composed of rhamnose-positive strains (formerly called atypical Yersinia enterocolitica or Yersinia enterocolitica-like. Curr. Microbiol. 4, 213-217. doi: 10.1007/BF02605859

Walter, M. C., Rattei, T., Arnold, R., Guldener, U., Munsterkotter, M., Nenova, K., et al. (2009). PEDANT covers all complete RefSeq genomes. Nucleic Acids Res. 37, 408-411. doi: 10.1093/nar/gkn749

Waterfield, N., Kamita, S. G., Hammock, B. D., and Ffrench-Constant, R. (2005). The Photorhabdus Pir toxins are similar to a developmentally regulated insect protein but show no juvenile hormone esterase activity. FEMS Microbiol. Lett. 245, 47-52. doi: 10.1016/j.femsle.2005.02.018
Waterfield, N. R., Wren, B. W., and Ffrench-Constant, R. H. (2004). Invertebrates as a source of emerging human pathogens. Nat. Rev. Microbiol. 2, 833-841. doi: 10.1038/nrmicro1008

Wauters, G., Le Minor, L., Chalon, A. M., and Lassen, J. (1972). Supplement to the antigenic schema of Yersinia enterocolitica. Ann. Inst. Pasteur. 122, 951-956.

Wilkinson, P., Waterfield, N. R., Crossman, L., Corton, C., Sanchez-Contreras, M., Vlisidou, I., et al. (2009). Comparative genomics of the emerging human pathogen Photorhabdus asymbiotica with the insect pathogen Photorhabdus luminescens. BMC Genomics 10:302. doi: 10.1186/1471-216410-302

Yang, G., Dowling, A. J., Gerike, U., Ffrench-Constant, R. H., and Waterfield, N. R. (2006). Photorhabdus virulence cassettes confer injectable insecticidal activity against the wax moth. J. Bacteriol. 188, 2254-2261. doi: 10.1128/JB.188.6.2254-2261.2006

Zhang, X., Hu, X., Li, Y., Ding, X., Yang Q., Sun Y., et al. (2014). XaxAB-like binary toxin from Photorhabdus luminescens exhibits both insecticidal activity and cytotoxicity. FEMS Microbiol. Lett. 350, 48-56. doi: 10.1111/1574-6968. 12321

Conflict of Interest Statement: The authors declare that the research was conducted in the absence of any commercial or financial relationships that could be construed as a potential conflict of interest.

Copyright ( $\odot 2018$ Springer, Sänger, Moritz, Felsl, Rattei and Fuchs. This is an openaccess article distributed under the terms of the Creative Commons Attribution License (CC BY). The use, distribution or reproduction in other forums is permitted, provided the original author(s) and the copyright owner(s) are credited and that the original publication in this journal is cited, in accordance with accepted academic practice. No use, distribution or reproduction is permitted which does not comply with these terms. 